\title{
Microstrip Tunable Bandpass Filter with the Colinear Resonators
}

\author{
Z. P. Wang, ${ }^{1}$ P. S. Hall, ${ }^{2}$ J. Kelly, ${ }^{3}$ and P. Gardner ${ }^{2}$ \\ ${ }^{1}$ School of Automation and Electrical Engineering, University of Science and Technology Beijing, Beijing 100083, China \\ ${ }^{2}$ Department of EECE, University of Birmingham, Birmingham B15 2TT, UK \\ ${ }^{3}$ Faculty of Science and Technology, Anglia Ruskin University, East Road, Cambridge CB1 1PT, UK
}

Correspondence should be addressed to Z. P. Wang; bee1030@163.com

Received 15 February 2013; Accepted 16 June 2013

Academic Editor: Mandeep Singh Jit Singh

Copyright (c) 2013 Z. P. Wang et al. This is an open access article distributed under the Creative Commons Attribution License, which permits unrestricted use, distribution, and reproduction in any medium, provided the original work is properly cited.

\begin{abstract}
This paper presents the lumped element circuit and transmission line equivalent circuit for a varactor-tuned bandpass filter. The filter consists of transmission lines, fixed capacitors, and a varactor diode. The colinear resonant sections, in this filter, are not configured in parallel, as they are in a conventional combline filter. For this reason the overall area of the filter is reduced. The passband of the filter can be tuned from $0.69 \mathrm{GHz}$ to $1.20 \mathrm{GHz}$ by varying the capacitance of the varactor diode. The insertion loss of this filter changes from $1.2 \mathrm{~dB}$ to $2.1 \mathrm{~dB}$ across this bandwidth.
\end{abstract}

\section{Introduction}

Tunable bandpass filters will play an important role in the future communication [1-3]. Compact, highly selective, and tunable filters with low insertion loss are widely required. Different tuning technologies have been developed, including varactor diode, mechanical tuning, microelectromechanical (MEMS) component, and $\mathrm{p}-\mathrm{i}-\mathrm{n}$ diode [4-10]. One of the most popular techniques for achieving continuous tuning by electrical means within a bandpass filter is to use a varactor diode. Hunter and Rhodes [11] report a tunable combline bandpass filter which can be tuned from $3.2 \mathrm{GHz}$ to $4.9 \mathrm{GHz}$ with a 3-5 dB insertion loss. Sánchez-Renedo et al. [12] present a developed combline filter structure with a continuous tunability for both the center frequency and bandwidth. El-Tanani and Rebeiz [13] describe a combline filter based on corrugated microstrip coupled line which offers miniaturized size. This filter has a frequency coverage of $1.32-1.89 \mathrm{GHz}$ with constant passband bandwidth across the tuning range. Tang and Hong [14] present a novel tunable bandpass filter based on a dual mode microstrip open-loop resonator. This filter offers constant absolute bandwidth and wide tuning range.

Most of the designs reported to date are based around coupled lines. Primarily these structures are coupled together magnetically. The radiation loss of the coupled line is high when the coupling is weak. In some application, it is not easy to establish the coupling matrix. This is the case for coplanar waveguide (CPW), for example.

This paper presents a novel tunable bandpass filter with colinear resonators. The filter is not based around parallel coupled lines. The overall area of this filter is smaller than the conventional combline filter. Equivalent circuits of the new filter are analyzed.

\section{Equivalent Circuit}

Figure 1 shows the proposed filter. The filter consists of microstrip lines, fixed capacitors, and a varactor diode. The main resonator is composed of a varactor diode and microstrip line $L_{2}$.

A lumped element equivalent circuit has been derived for this filter. The equivalent circuit is shown in Figure 2. The basic resonator is represented by $L_{i 2}$ and capacitance of the varactor $\left(C_{2}\right)$. The external coupling is controlled by the " $L$ " shaped circuit located on either side of this resonator.

The circuit element values are presented in Table 1. The $S$ parameters of the lumped element equivalent circuit are calculated in MATLAB 6.5, as shown in Figure 3. It can be observed from Figure 3 that the centre frequency of the passband can be tuned from $0.58 \mathrm{GHz}$ to $1.26 \mathrm{GHz}$ by varying 


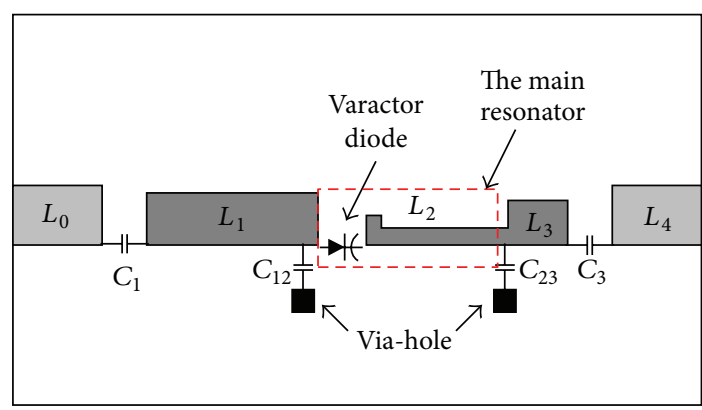

FIgURE 1: The tunable bandpass filter.

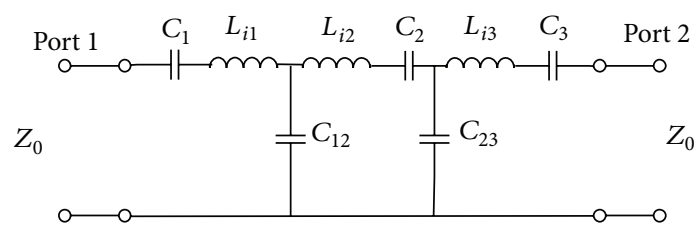

FIGURE 2: Lumped element equivalent circuit.

TABLE 1: Equivalent circuit element values.

\begin{tabular}{lc}
\hline Element & Value \\
\hline$C_{1}$ & $3.3 \mathrm{pf}$ \\
$C_{2}$ & $C_{v}$ \\
$C_{3}$ & $3.3 \mathrm{pf}$ \\
$C_{12}$ & $6.8 \mathrm{pf}$ \\
$C_{23}$ & $6.8 \mathrm{pf}$ \\
$L_{i 1}$ & $5 \mathrm{nH}$ \\
$L_{i 2}$ & $20 \mathrm{nH}$ \\
$L_{i 3}$ & $5 \mathrm{nH}$ \\
\hline
\end{tabular}

the capacitance of $C_{2}$ from $15 \mathrm{pf}$ to $1 \mathrm{pf}$. The absolute $3 \mathrm{~dB}$ bandwidth of this filter is $100 \pm 2 \mathrm{MHz}$ across the tuning range. According to computer simulation the return loss is better than $20 \mathrm{~dB}$ across the entire tuning range.

Figure 4 shows a transmission line equivalent circuit developed from the lumped element equivalent circuit. The capacitors retain their value and position in the transmission line circuit. The inductors $L_{i 1}, L_{i 2}$, and $L_{i 3}$ in the lumped element circuit are replaced by sections of transmission line $\mathrm{TX}_{1}, \mathrm{TX}_{2}$, and $\mathrm{TX}_{3}$, respectively. Transmission through the filter, that is, $S_{21}$, can be deduced with reference to the $A B C D$ matrix.

The $A B C D$ matrix for the series capacitor $C_{1}$ is

$$
A_{1}=\left[\begin{array}{cc}
1 & Z_{\text {cap } 1} \\
0 & 1
\end{array}\right]
$$

where $Z_{\text {cap } 1}=1 / j \omega C_{1}$.

The $A B C D$ matrix of transmission line $\mathrm{TX}_{1}$ is

$$
A_{2}=\left[\begin{array}{cc}
\cos \beta l_{1} & j Z_{1} \sin \beta l_{1} \\
j Y_{1} \sin \beta l_{1} & \cos \beta l_{1}
\end{array}\right],
$$

where $Z_{1}, Y_{1}$ are the characteristic impedance and admittance of the transmission line, $\beta$ is the transmission line phase constant, and $l_{1}$ is the length of the transmission line.

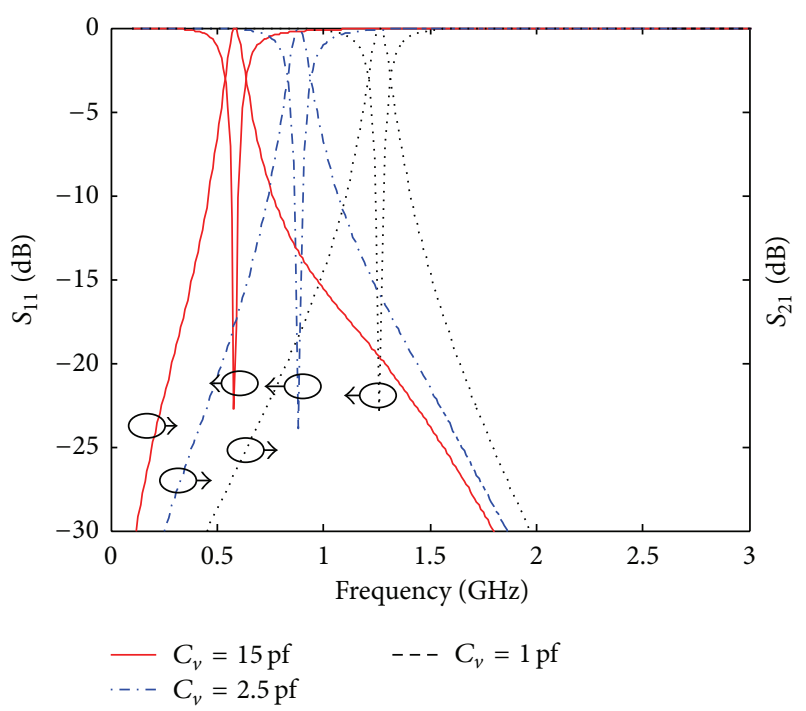

FIGURE 3: Calculated $S$ parameters.

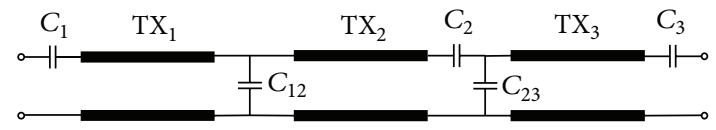

FIgURE 4: Transmission line equivalent circuit.

The $A B C D$ matrix of the parallel capacitor $C_{12}$ is

$$
A_{3}=\left[\begin{array}{cc}
1 & 0 \\
Y_{\text {cap } 12} & 1
\end{array}\right]
$$

where $Y_{\text {cap12 }}=j \omega C_{12}$.

The $A B C D$ matrices of the other capacitors and transmission lines follow in the same way, respectively.

According to matrix algebra the $A B C D$ matrix of the whole circuit shown in Figure 3 can be described as follows:

$$
A=A_{1} A_{2} A_{3} A_{4} A_{5} A_{6} A_{7} A_{8}=\left[\begin{array}{ll}
a & b \\
c & d
\end{array}\right] .
$$

The $S$ parameter matrix can be derived from the $A B C D$ matrix as follows:

$$
S=\left[\begin{array}{cc}
\frac{a+b / Z_{0}-c Z_{0}-d}{a+b / Z_{0}+c Z_{0}+d} & \frac{2(a d-b c)}{a+b / Z_{0}+c Z_{0}+d} \\
\frac{2}{a+b / Z_{0}+c Z_{0}+d} & \frac{-a+b / Z_{0}-c Z_{0}+d}{a+b / Z_{0}+c Z_{0}+d}
\end{array}\right] .
$$

The lengths of the transmission line sections $\mathrm{TX}_{1}, \mathrm{TX}_{2}$, and $\mathrm{TX}_{3}$ were set to $0.12,0.14$, and 0.03 wavelengths at $1 \mathrm{GHz}$, respectively. Normally one would expect the length of the input and output lines of a filter to be identical. In this case, however, the lengths of $\mathrm{TX}_{1}$ and $\mathrm{TX}_{3}$ are different. This is mainly caused by the asymmetry of the main resonator (formed by $\mathrm{TX}_{2}$ and $C_{2}$ ). The length of $\mathrm{TX}_{3}$ is set shorter than that of $\mathrm{TX}_{1}$. This makes the passband bandwidth constant, across the entire tuning range. The characteristic impedance of $\mathrm{TX}_{1}$ and $\mathrm{TX}_{3}$ is set to $50 \Omega$. The characteristic impedance 
of $\mathrm{TX}_{2}$, however, is set to $100 \Omega$. This is necessary in order to achieve a high inductance value from a short length of transmission line.

Figure 5 shows the calculated results from (5) using MATLAB 6.5. It can be observed that the centre frequency of the passband can be tuned from $0.65 \mathrm{GHz}$ to $1.24 \mathrm{GHz}$ by varying the capacitance of $C_{2}$ from $15 \mathrm{pf}$ to $1 \mathrm{pf}$. The absolute $3 \mathrm{~dB}$ bandwidth of this filter varies from $100 \mathrm{MHz}$ to $97 \mathrm{MHz}$ across the tuning range. The $3 \mathrm{~dB}$ bandwidth is nearly constant as the center frequency of the passband is changed.

\section{Microstrip Line Filter Design}

A microstrip line tunable bandpass filter is developed based on transmission line circuit shown in Figure 4 . The structure of the filter is shown in Figure 1. $L_{0}$ and $L_{4}$ are $50 \Omega$ transmission lines. Both of these lines are $3.38 \mathrm{~mm}$ wide and $10 \mathrm{~mm}$ long. However the length of $L_{0}$ and $L_{4}$ has no impact on the performance of this design. $L_{1}, L_{2}$, and $L_{3}$ are 3 resonant sections. The length and width of these 3 resonant sections are optimized to provide constant bandwidth across the whole tuning range. $L_{1}$ is $3.05 \mathrm{~mm}$ wide and $24.6 \mathrm{~mm}$ long. $L_{2}$ is $0.46 \mathrm{~mm}$ wide and $20 \mathrm{~mm}$ long. A $2 \mathrm{~mm}$ by $2 \mathrm{~mm}$ pad is introduced at the end of $L_{2}$ nearest $L_{1}$. This pad provides a surface on which to solder the varactor diode. $L_{3}$ is $2.44 \mathrm{~mm}$ wide and $8.2 \mathrm{~mm}$ long. The resonator within this filter is $52.8 \mathrm{~mm}$ long (i.e., nearly $\lambda_{\text {eff }} / 4$ at $1.2 \mathrm{GHz}$ ). Two chip capacitors, labeled $C_{1}$ and $C_{3}$ (ATC 600S, $C=3.3 \mathrm{pf}$ ), are used to connect the transmission lines $L_{0}$ and $L_{4}$ to $L_{1}$ and $L_{3}$ together. A second pair of chip capacitors, labeled $C_{12}$ and $C_{23}$ (ATC 600S, $C=$ $6.8 \mathrm{pf}$ ), are used to connect $L_{1}$ and $L_{2}$ to the grounding vias.

Two $10 \mathrm{k} \Omega$ RF-choke resistors are used to connect the resonator to the bias line. The filter is fabricated on a Taconic TLY-3 substrate (i.e., $h=1.14 \mathrm{~mm}, \varepsilon_{r}=2.33$, and $\tan \delta=$ 0.0009). An MV31009 surface mount varactor diode, from MDT Corporation, was used in the prototype circuit. The relationship between the voltage and the capacitance is given in Table 2.

The equivalent series resistance of the varactor is $0.455 \Omega$. The $S$ parameters of the microstrip line filter can be calculated using (5), as mentioned earlier. The $A B C D$ matrix of the varactor diode can be represented as follows:

$$
A_{6}=\left[\begin{array}{cc}
1 & \frac{1}{j \omega C_{2}}+0.455 \\
0 & 1
\end{array}\right] .
$$

Figures 6(a) and 6(b) show the scattering parameters obtained through simulation using CST MWS. The filter's passband centre frequency can be tuned from $0.69 \mathrm{GHz}$ to $1.24 \mathrm{GHz}$ by varying the reverse voltage applied to the varactor diode $\left(C_{2}\right)$. The absolute $3 \mathrm{~dB}$ bandwidth of this filter varies from $125 \mathrm{MHz}$ to $136 \mathrm{MHz}$ as the filter is tuned. The insertion loss is nearly $0.8 \mathrm{~dB}$, and the return loss is better than $18 \mathrm{~dB}$ across the whole tuning range.

The capacitances of $C_{12}$ and $C_{23}$ control the loaded Qfactor of the filter (see Figure 1). Increasing the capacitance increases the loaded $Q$-factor. In order to minimize the total number of varactors required and hence the overall insertion loss we demonstrate a 1-pole tunable bandpass filter. In a
TABLE 2: Capacitance versus reverse voltage (MV31009).

\begin{tabular}{lc}
\hline Voltage $(\mathrm{V})$ & Capacitance $(\mathrm{pf})$ \\
\hline 0 & 22.08 \\
3 & 4.77 \\
5 & 3.01 \\
7 & 2.18 \\
9 & 1.71 \\
\hline
\end{tabular}

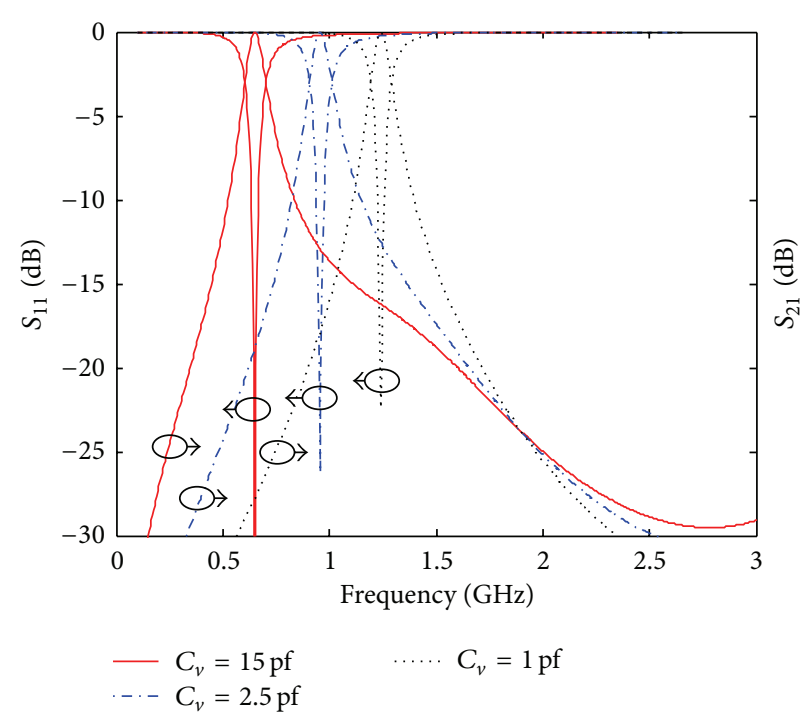

FIgURE 5: Calculated $S$ parameters.

multipole bandpass filter these capacitors would provide a convenient way by which to vary the coupling coefficient over a wider range of values. It is also possible to control the bandwidth of the passband by tuning the coupling capacitance.

\section{Measurement Results}

Figure 7 shows a prototype of the tunable bandpass filter. Two SMA connectors are soldered on each side of the filter. The reverse voltage is applied across the bias lines depicted in Figure 7. Agilent 8720 VNA is used in this measurement. Figure 8(a) shows measured $S_{21}$ results. The centre frequency of the passband can be tuned from $0.69 \mathrm{GHz}$ to $1.20 \mathrm{GHz}$. The insertion loss varies from $1.2 \mathrm{~dB}$ to $2.1 \mathrm{~dB}$ as the filter is tuned throughout this range. The insertion loss is suppressed below $-30 \mathrm{~dB}$ from $0.1 \mathrm{GHz}$ to $2.5 \mathrm{GHz}$. According to the measurement results the $3 \mathrm{~dB}$ bandwidth of the filter changes from $118 \mathrm{MHz}$ to $69 \mathrm{MHz}$, as the filter is tuned throughout its full range. Compared with the simulation results, the measurement results indicate that the passband bandwidth of the filter becomes narrower as the filter is tuned towards higher frequencies. The insertion loss observed through the measurement is also higher than that predicted by simulation. These differences are mainly due to an increase in the parasitic resistance and inductance of the fixed capacitors and the varactor diode. The simulation results show that the tuning range is restricted by the variation in the capacitance of the varactor diodes. 


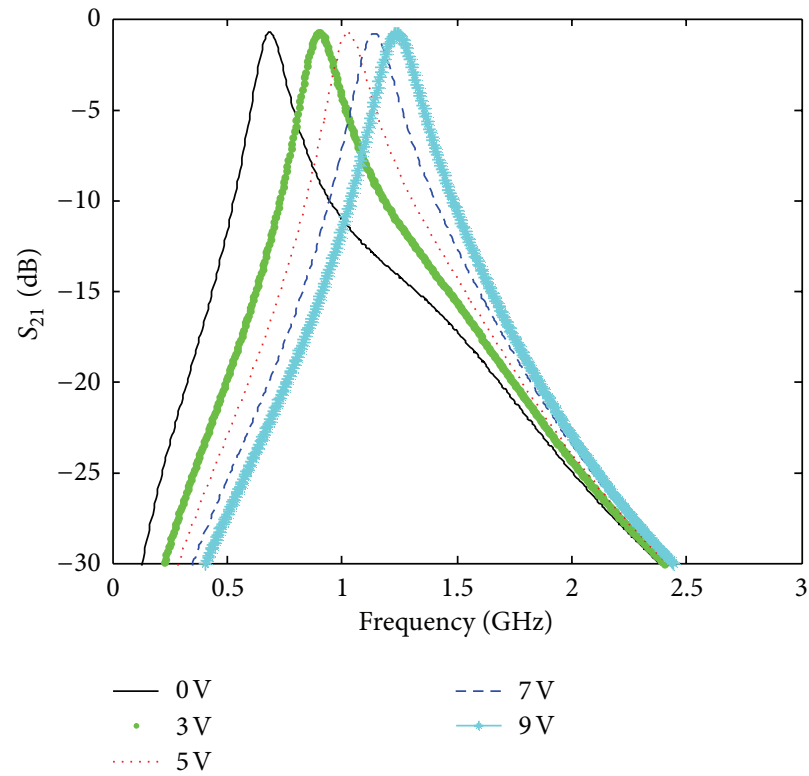

(a)

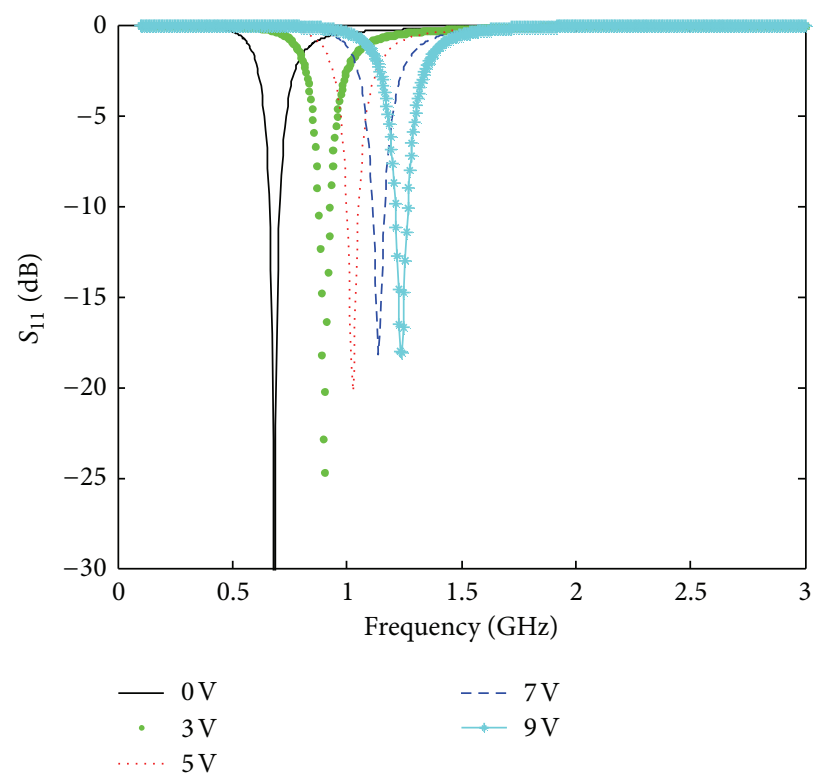

(b)

FIGURE 6: Simulated $S$ parameters.

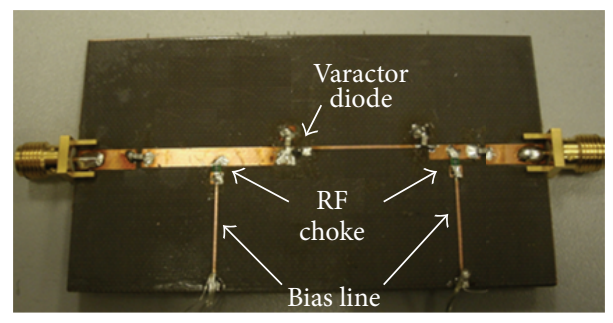

Figure 7: Prototype of the filter.

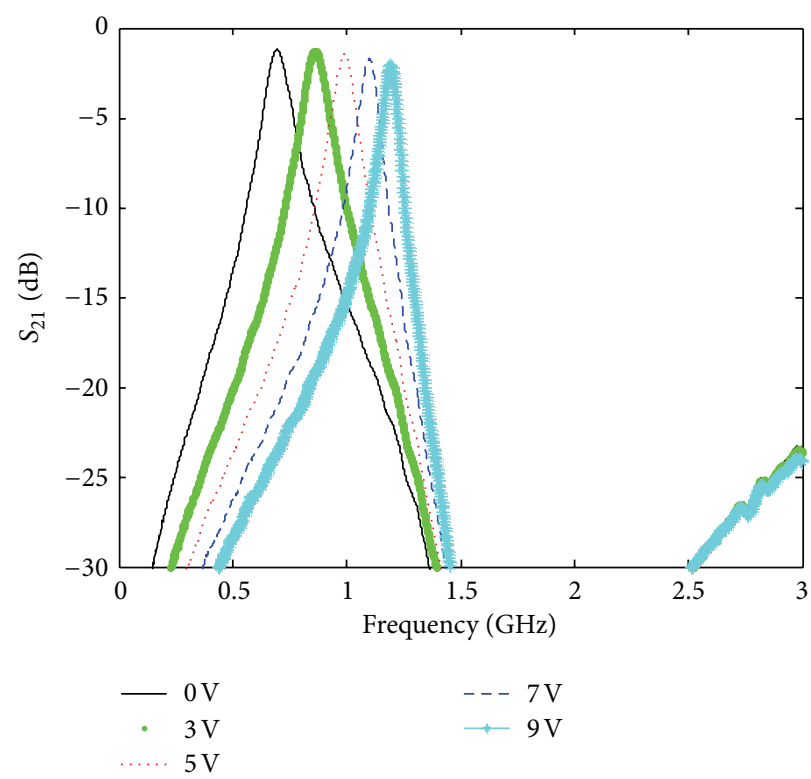

(a)

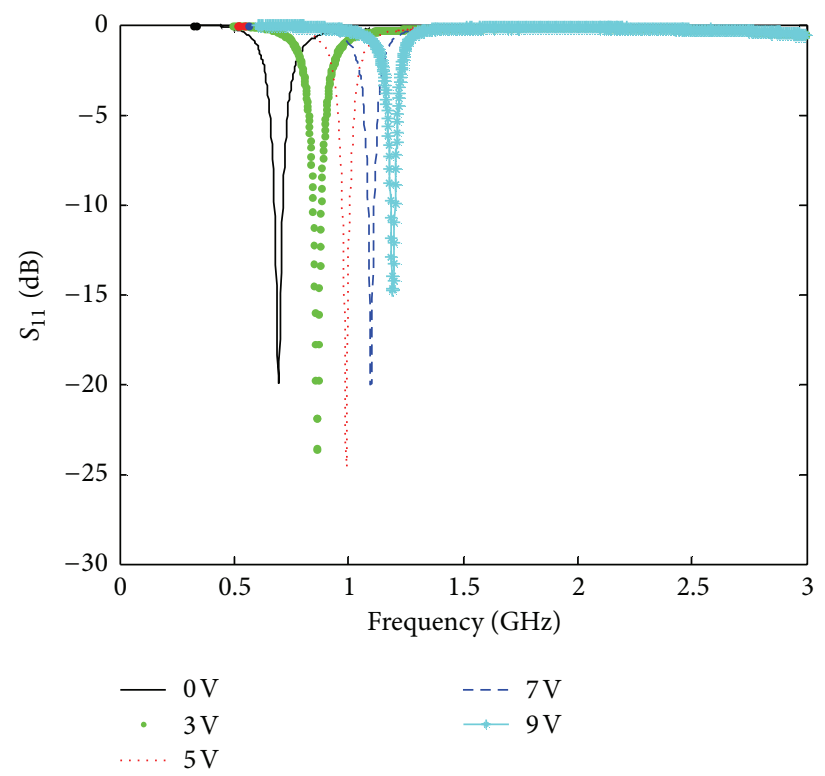

(b)

FIGURE 8: Measured $S$ parameters. 
Figure $8(\mathrm{~b})$ shows the measured return loss. Inspection of the results reveals that the return loss is better than $14.8 \mathrm{~dB}$ for all of the tuning states demonstrated.

\section{Conclusion}

This paper presents a new form of tunable bandpass filter with colinear resonators. Unlike many of the other tunable filters in the literature the filter is not based around coupled lines. The equivalent circuits of the new filter are analyzed. Experimental results show that the passband centre frequency can be tuned from $0.69 \mathrm{GHz}$ to $1.20 \mathrm{GHz}$ by varying the capacitance of the varactor from $22.08 \mathrm{pf}$ to $1.71 \mathrm{pf}$.

\section{Conflict of Interests}

The authors declare that they have no conflict of interests.

\section{Acknowledgment}

The authors are grateful to China Scholarship Council (CSC) for sponsorship for Z. P. Wang.

\section{References}

[1] P. W. Wong and I. C. Hunter, "A new class of low-loss highlinearity electronically reconfigurable microwave filter," IEEE Transactions on Microwave Theory and Techniques, vol. 56, no. 8, pp. 1945-1953, 2008.

[2] P. W. Wong and I. Hunter, "Electronically tunable filters," IEEE Microwave Magazine, vol. 10, no. 6, pp. 46-54, 2009.

[3] J. S. Hong and M. J. Lancaster, Microstrip Filters for RF/Microwave Applications, Wiley, New York, NY, USA, 2001.

[4] J. Nath, D. Ghosh, J. Maria et al., "An electronically tunable microstrip bandpass filter using thin-film Barium-StrontiumTitanate (BST) varactors," IEEE Transactions on Microwave Theory and Techniques, vol. 53, no. 9, pp. 2707-2712, 1982.

[5] R. Levy and P. Petre, "Design of CT and CQ filters using approximation and optimization," IEEE Transactions on Microwave Theory and Techniques, vol. 49, no. 12, pp. 2350-2356, 2001.

[6] J. Sigman, C. D. Nordquist, P. G. Clem, G. M. Kraus, and P. S. Finnegan, "Voltage-controlled $\mathrm{Ku}-\mathrm{B}$ and and $\mathrm{X}$-band tunable combline filters using barium-strontium-titanate," IEEE Microwave and Wireless Components Letters, vol. 18, no. 9, pp. 593595, 2008.

[7] A. Pothier, J. Orlianges, G. Zheng et al., "Low-loss 2-bit tunable bandpass filters using MEMS DC contact switches," IEEE Transactions on Microwave Theory and Techniques, vol. 53, no. 1, pp. 354-360, 2005.

[8] F. A. Miranda, G. Subramanyam, F. W. van Keuls, R. R. Romanofsky, J. D. Warner, and C. H. Mueller, "Design and development of ferroelectric tunable microwave components for ku- and k-band satellite communication systems," IEEE Transactions on Microwave Theory and Techniques, vol. MTT48, no. 7, pp. 1181-1189, 2000.

[9] P. M. Suherman, T. J. Jackson, Y. Y. Tse et al., "Microwave properties of $\mathrm{Ba}_{0.5} \mathrm{Sr}_{0.5} \mathrm{TiO}_{3}$ thin film coplanar phase shifters," Journal of Applied Physics, vol. 99, no. 10, Article ID 104101, 7 pages, 2006.

[10] S. Park and G. M. Rebeiz, "Low-loss two-pole tunable filters with three different predefined bandwidth characteristics," IEEE
Transactions on Microwave Theory and Techniques, vol. 56, no. 5, pp. 1137-1148, 2008.

[11] I. C. Hunter and J. D. Rhodes, "Electronically tunable microwave bandpass filters," IEEE Transactions on Microwave Theory and Techniques, vol. 30, no. 9, pp. 1354-1360, 1982.

[12] M. Sánchez-Renedo, R. Gómez-Garcia, J. I. Alonso, and C. Briso-Rodríguez, "Tunable combline filter with continuous control of center frequency and bandwidth," IEEE Transactions on Microwave Theory and Techniques, vol. 53, no. 1, pp. 191-199, 2005.

[13] M. A. El-Tanani and G. M. Rebeiz, "Corrugated microstrip coupled lines for constant absolute bandwidth tunable filters," IEEE Transactions on Microwave Theory and Techniques, vol. 58, no. 4, pp. 956-963, 2010.

[14] W. Tang and J. Hong, "Varactor-tuned dual-mode bandpass filters," IEEE Transactions on Microwave Theory and Techniques, vol. 58, no. 8, pp. 2213-2219, 2010. 

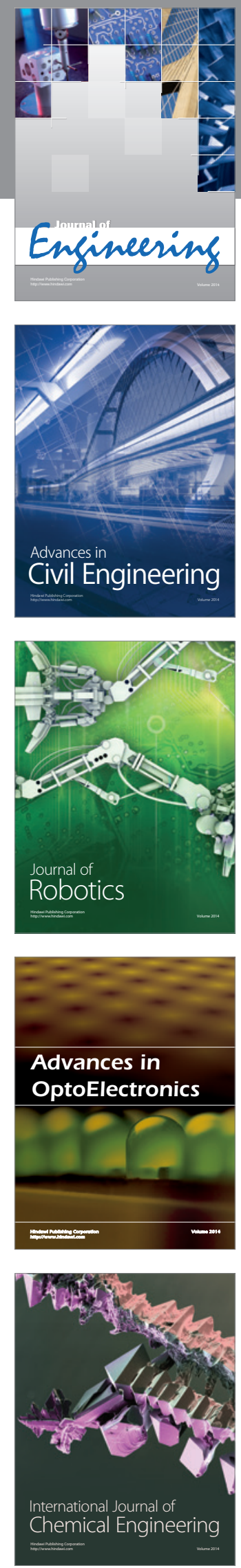

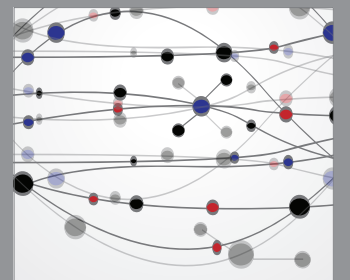

The Scientific World Journal
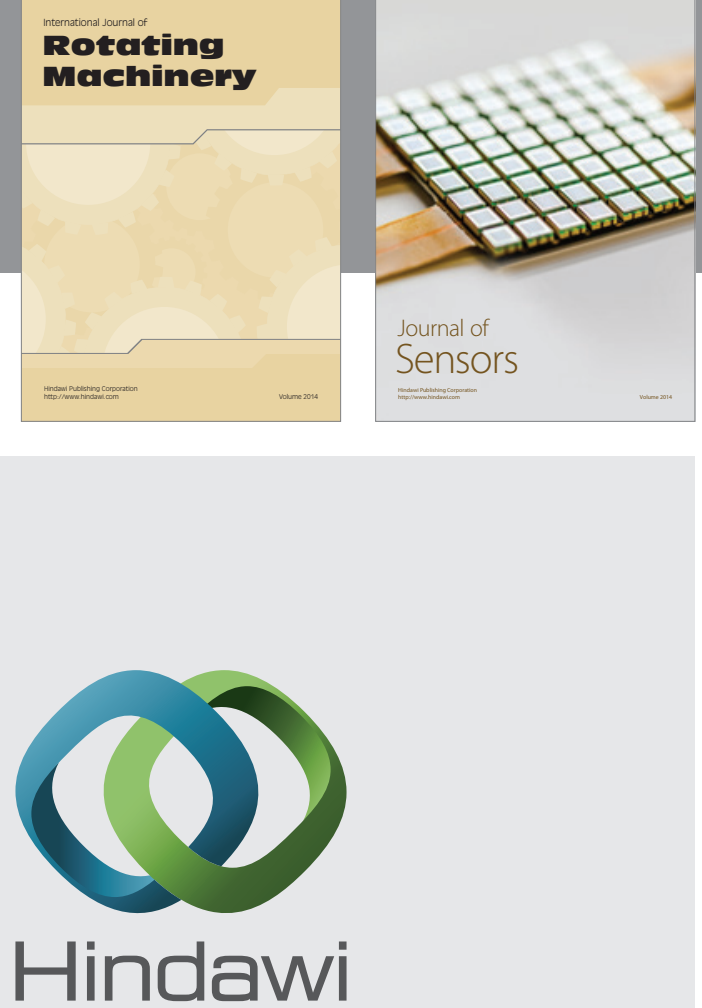

Submit your manuscripts at http://www.hindawi.com
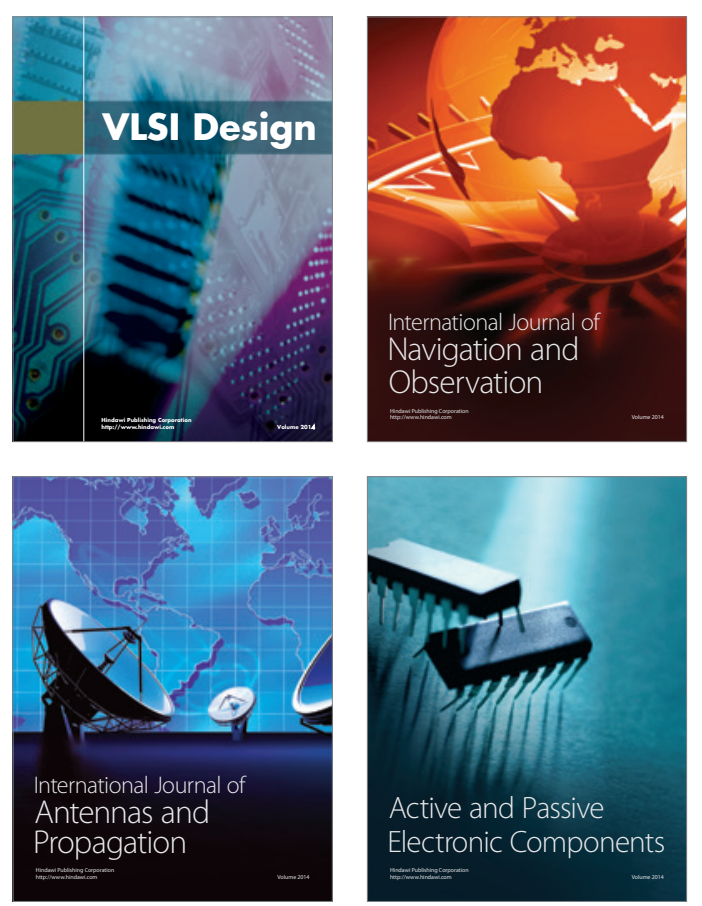
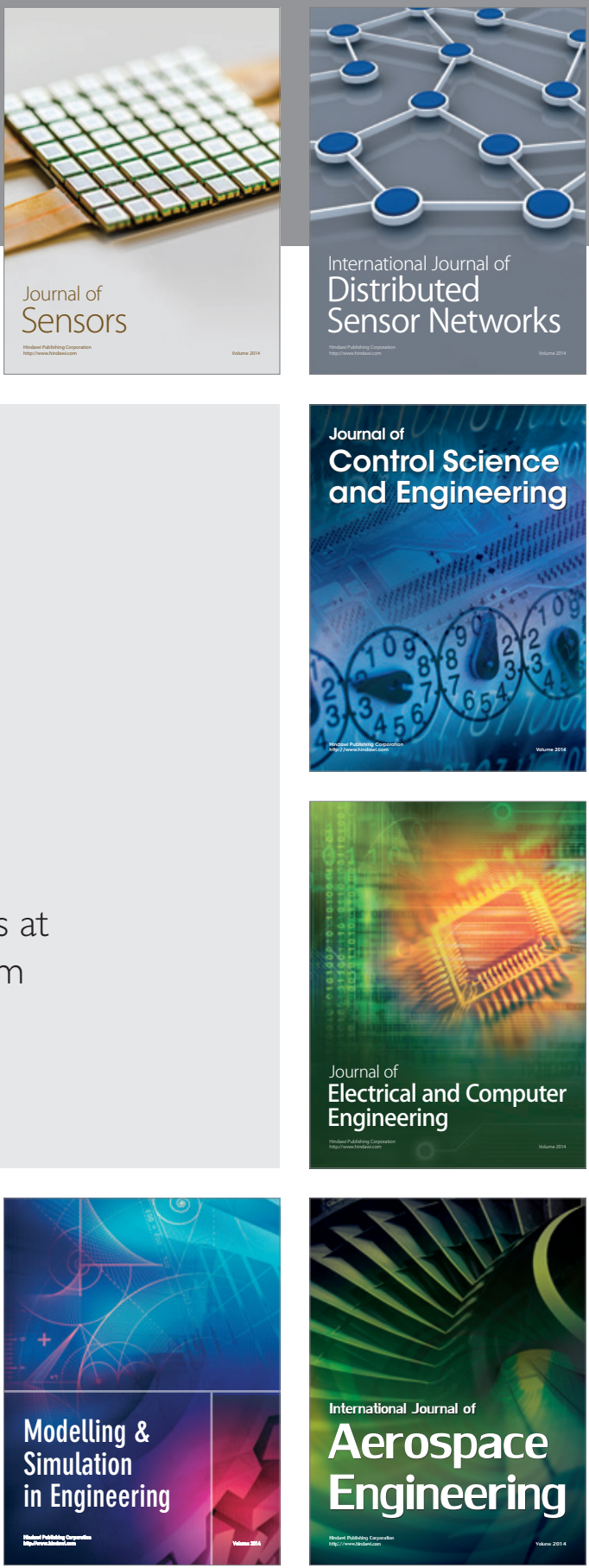

Journal of

Control Science

and Engineering
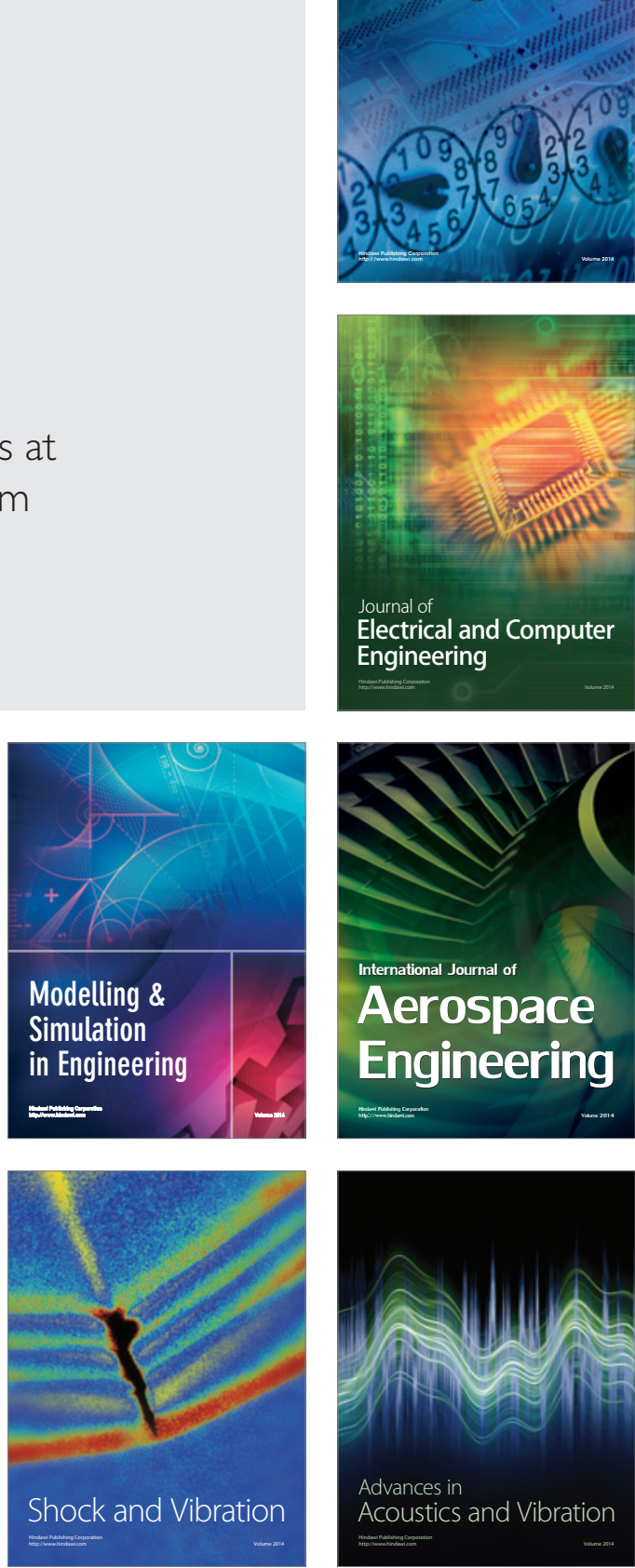